\title{
INVESTIGATION OF PRESSING AND EJECTION PERFORMANCE OF FRICTION-REDUCING POWDER-COMPACTION TOOL COATINGS
}

\author{
${ }^{1}$ Bernd-Arno BEHRENS, ${ }^{1}$ Kai BRUNOTTE, ${ }^{1}$ Tom PETERSEN, ${ }^{1}$ Dieter BOHR \\ ${ }^{1}$ Leibniz University Hannover, Institute of Forming Technology and Machines, Hannover Germany, EU; \\ behrens@ifum.uni-hannover.de, brunotte@ifum.uni-hannover.de, petersen@ifum.uni-hannover.de, \\ bohr@ifum.uni-hannover.de
}

https://doi.org/10.37904/metal.2021.4179

\begin{abstract}
Pressing in dies followed by sintering is the most commonly used process for shaping metal powders into components. The mechanical properties (e.g. tensile and fatigue strength) of the final sintered component depend on the green-compact properties resulting from the compaction process. Apart from the powder material used, process-specific factors, such as geometry complexity, compaction pressure and lubrication strategy, have a major impact on the properties of the green compact. The lubrication strategy is also decisive for the economic efficiency of the process as it influences the service life of the tools.

Friction-reducing powder-compaction tool coatings (e.g. diamond-like-carbon-based / DLC) provide the potential to positively influence the lubrication conditions during compaction and ejection, thus simultaneously improving product quality and service life. In this study, experimental investigations on the performance of friction-reducing coatings in the die pressing of steel powder $(\mathrm{Fe}+0.6 \mathrm{wt} \% \mathrm{C}$ ) with and without admixed lubricant (AncorLube, GKN Hoeganaes) are presented. The results are evaluated by force-displacement measurements, which allows for a more profound analysis of compaction and ejection behaviour. It is shown that the application of the coatings reduces the ejection loads significantly when no admixed lubricant is used, and moderately when lubricant is admixed. However, without lubricant, wear still occurs after a few pressing cycles, so it cannot be completely avoided.
\end{abstract}

Keywords: DLC-coating, powder metallurgy, metal powder compaction, lubrication

\section{INTRODUCTION}

The main advantage of powder metallurgy (PM) over other manufacturing processes is the possibility to massproduce structural components with tight dimensional tolerances and the required mechanical properties in a cost-effective way [1]. In addition, PM offers ecological advantages due to its high material utilisation and low energy consumption [2].

In conventional PM processes, powder consolidation is divided into shaping by mechanical compaction and subsequent sintering to form a material bond. The PM shaping process most commonly used in the industry is the double-sided compaction in dies [1]. In this process, the powder is filled into a die and then compacted evenly from both sides by opposing punches. Finally, the so-called green compact is ejected by the lower punch.

The properties of the green compact are decisive for the final component properties [3]. Thus, the green density impacts the final density of the component after sintering and therefore the mechanical properties, such as tensile strength, elongation at break and fatigue strength [4]. The green density is in turn governed by the compaction process and depends on material- and process-specific variables [5]. In this regard, important material-specific parameters are grain geometry, grain size and the powder material used [1]. On the process side, the compaction pressure, the ejection force [6] and the lubrication strategy for friction reduction [7] are 
crucial. Usually, a lubricant or pressing aid is admixed to the powder in small quantities $(<1 \mathrm{wt} \%)$ and the powder is then thoroughly mixed (powder lubrication). With optimal dosage, the powder compressibility and thus the green density and homogeneity can be increased [8]. Consequently, the reduction of friction has a positive impact on process stability and component properties [9].

In order to evaluate the friction conditions during die compaction in practice, the ejection behaviour is often investigated by analysing the force-displacement or time diagram [10]. Many studies exist on this subject, most of which focus on the variation of the lubricant added or its quantity. Larsson and Ramstedt compared different types of lubricants (metal soap, amides and composite lubricant) in their investigations and evaluated each of them with regard to pressing and ejection behaviour [11]. Paris et al. follow up on this with their research and provide a review of commercially available high-performance (composite) lubricants by comparing those with a well-known and widely used EBS wax Acrawax C [12]. To further increase lubrication performance and efficiency, Larsson and Knutsson investigated the influence of heated tools (up to $90^{\circ} \mathrm{C}$ ) on the pressing and ejection behaviour for different composite lubricants and showed the high potential of this method for making high-density PM parts [13].

Besides the choice of the appropriate lubricant, the use of friction-reducing coatings is another promising approach to positively influencing the friction conditions. In this context, Ernst investigated - among other things - the influence of different coatings on the compaction and frictional forces during pressing and calibration [14]. The use of a DLC coating (diamond-like-carbon) reduced the (over the entire compaction and ejection process) averaged frictional shear stresses occurring on the die and finally resulted in a significant increase in tool life. However, the influence of the different coatings under varying process parameters (compaction pressure, lubricant and lubricant quantity) was not investigated. Bonnefoy et al., on the other hand, studied these correlations with the help of a sliding piece device, which allows fast predictions regarding the application behaviour for the parameter combinations selected [15]. Again, the DLC-based coatings (in combination with admixed lubricant) performed best in terms of friction behaviour. However, due to the modellike test method, no statements could be made about the practical compaction and ejection performance.

A further model-based method was developed by Olsson using a modified scratch tester. The setup allows for measuring the fretting resistance between metal powders and tool materials [16]. By this means, the tribological performance of different surface conditions could be investigated under conditions similar to powder pressing, achieving the lowest initial and steady-state friction values with DLC-based coatings [17]. Here, too, no quantitative statements could be made about the practical compaction and ejection behaviour of the coatings due to the model-based test procedure.

\subsection{Objective and Approach}

In this paper, the ejection performance of friction-reducing coatings in die compaction is investigated, focussing on the correlation between lubrication strategies (conventional vs. coating), compaction and ejection behaviour.

Within the investigations, iron-powder mixtures (with and without admixed lubricant) were compacted doublesided under varying compaction pressure and surface modification (with and without coating). To evaluate the results, force-displacement profiles were recorded during powder compaction and ejection and characteristic values (stripping and sliding shear stress) were calculated from them.

\section{MATERIALS AND METHODS}

The tests were performed on a path-controlled, hydraulic multi-axis powder press HPM 200 E2 from SMS Meer using cylindrical dies (inner diameter $\times$ height $=40 \mathrm{~mm} \times 90 \mathrm{~mm}$ ) made of cold work steel (1.2379, AISI D2). The dies were quenched and tempered to $60 \mathrm{HRC}$ (Rockwell Hardness, c-scale) and the inner lateral surfaces were polished to $R_{z}<1 \mu \mathrm{m}$. The test parameters varied are summarised in Table 1 . Three surface 
configurations (2 coatings [18; 19], 1 without coating) and two powder versions (with and without admixed lubricant [20]) were investigated.

Table 1 Varied parameters for compaction and ejection tests

\begin{tabular}{|c|c|c|c|}
\hline \multirow{2}{*}{ Surface configuration } & \multirow{2}{*}{$\begin{array}{l}\text { Powder material (Ancorsteel }{ }^{\mathrm{TM}} \\
\text { 1000B with } 0.6 \text { wt } \% \text { Graphite UF4) }\end{array}$} & \multicolumn{2}{|c|}{$\begin{array}{c}\text { Filling height } h_{\text {fill }} \text { or compaction ratio } \\
h_{\text {fill }} / h_{\text {press }}\left(h_{\text {press }}=37 \mathrm{~mm}\right)\end{array}$} \\
\hline & & $\mathbf{h}_{\text {fill }}$ in $\mathbf{m m}$ & $\mathbf{h}_{\text {fill }} / \mathbf{h}_{\text {press }}$ \\
\hline $\begin{array}{c}\text { no coating } \\
\text { MoS2-based (MOX2®) } \\
\text { DLC-based (CARBON-X®) }\end{array}$ & $\begin{array}{l}\text { no admixed lubrication } \\
0.5 \mathrm{wt} \% \text { AncorLube }\end{array}$ & $\begin{array}{l}68.35 \\
74.35 \\
78.15\end{array}$ & $\begin{array}{l}1.8 \\
2.0 \\
2.1\end{array}$ \\
\hline
\end{tabular}

In order to obtain identical specimen geometries at varying compaction pressures, the compacts were pressed under variation of the filling height as shown in (Table 1). Each combination was tested 10 times and monitored using two strain-gauge-based force transducers and two draw-wire sensors. The parameter combinations without lubricant at compression ratios 2.0 and 2.1 could not be carried out, as will be explained under results.

Figure 1 shows, as an example, the data recorded of the upper and lower punch during the whole compaction cycle versus time as well as an enlarged view of the ejection process, which forms the focus of this work.
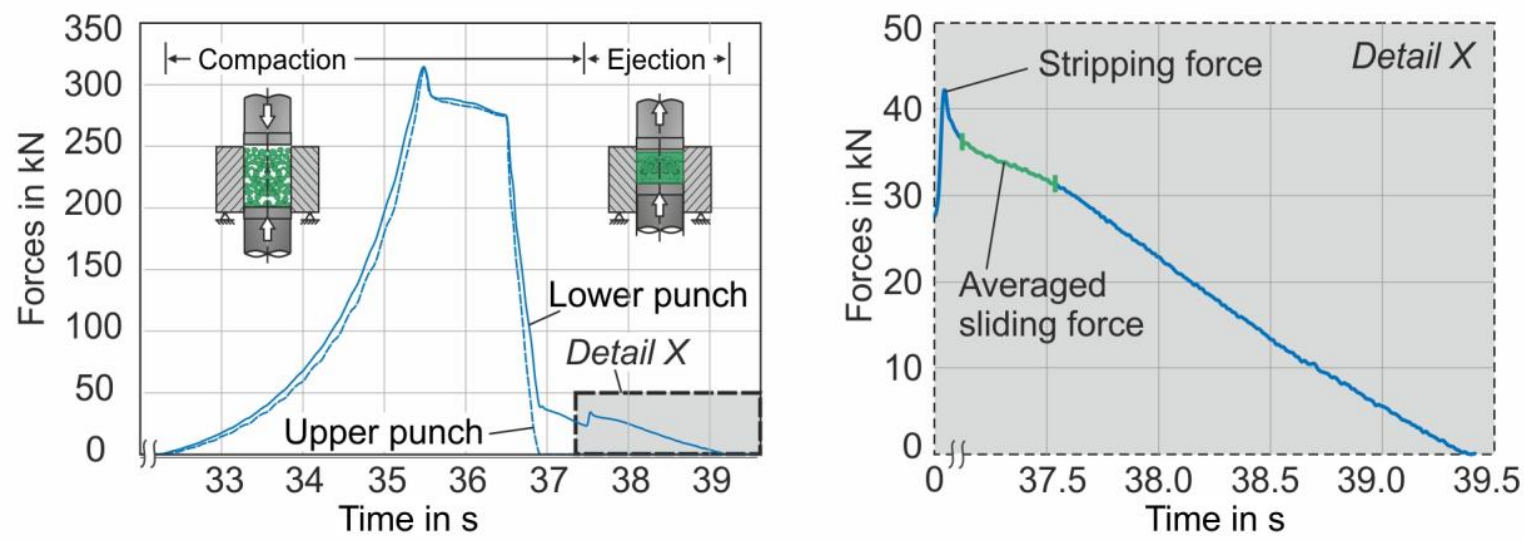

Figure 1 Lower and upper punch forces as a function of time for a compaction cycle (left) and enlarged view of ejection process (right)

In order to characterise the frictional behaviour quantitatively, two characteristic sections were examined in the ejection processes, in accordance with the work of Paris et al (Figure 1, right) [12]. The first is the initial area where the stripping force has to be applied at the beginning of the ejection in order to overcome the static friction between compact and die wall. The second is the area where the compact is being moved inside the die towards the opening and is still completely enclosed by the cavity. By averaging in this area, the sliding force was calculated. For a geometry-independent evaluation, both values were related to the friction surface, i.e. the final lateral surface of the compact, to finally calculate the stripping and sliding shear stresses.

\section{RESULTS AND DISCUSSION}

Figure 2 (left) shows the mean ejection curves (each averaged from 10 tests) of the parameter combinations investigated with admixed lubricant. For a better overview and comparison, the characteristic values as described above are shown on the right in the form of a bar chart. 
When examining the compaction ratios for each die configuration, as expected, an increase in the curves and characteristic values can be seen due to the associated higher compaction pressures. At a compaction ratio of 1.8, the lowest stripping and sliding shear stresses are required when the MoS $_{2}$-based coating is used, followed by the DLC coating and finally the variant without coating (Figure 2, left). By increasing the compaction ratio to 2.0, the shear stresses rise significantly, although the aforementioned differences between the die configurations remain. A further increase to 2.1 results in an increase only for the coated variants, with the $\mathrm{MoS}_{2}$-based variant still performing best.

When observing the corresponding ejection curves (left), it is noticeable that the transition from the stripping peak to the sliding area is significantly flatter in the case of the $\mathrm{MoS}_{2}$-based coating compared to the DLC coating and the variant without coating. Although the exact reasons for this are unknown, such a curve characteristic is usually associated with more favourable friction conditions [14], which is consistent with the quantitative results.
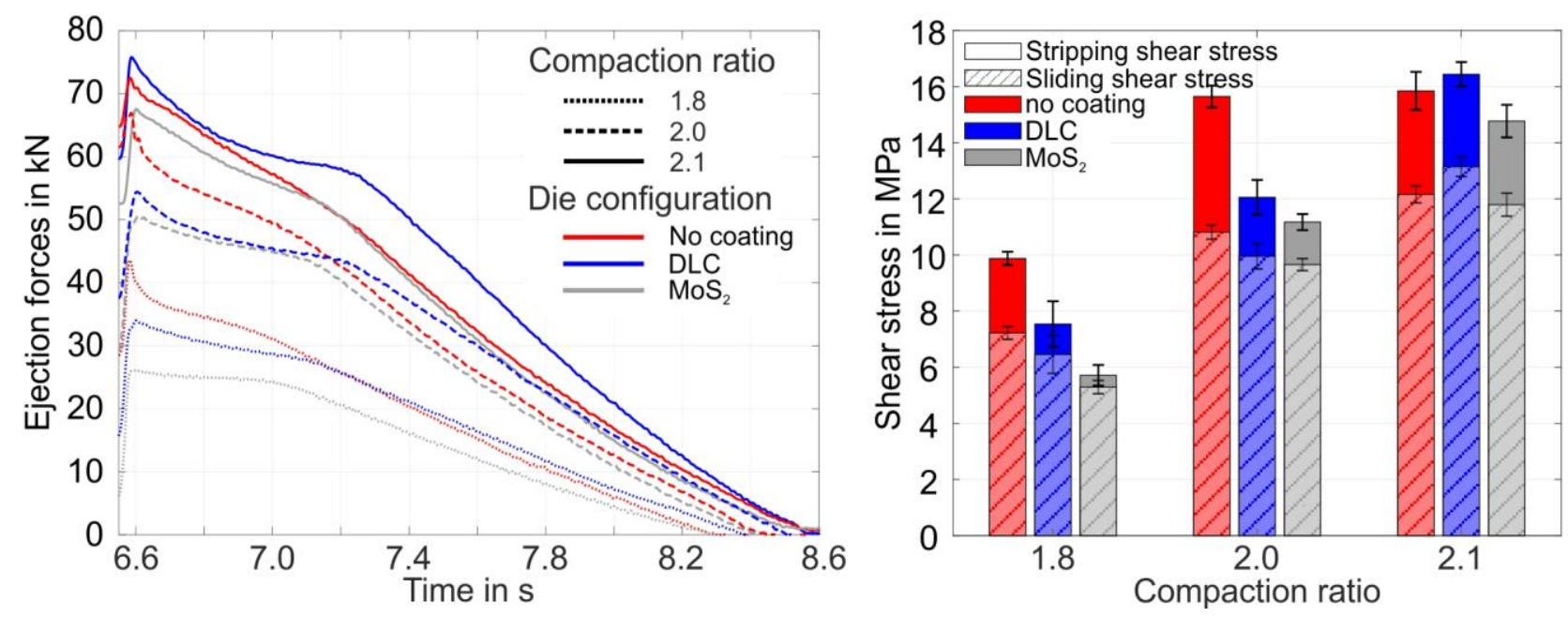

Figure 2 Averaged ejection curves (left) and associated stripping and sliding shear stresses (right)

In order to investigate the ejection behaviour as a function of the compaction behaviour, the calculated stripping shear stresses of all tests were plotted in (Figure $\mathbf{3}$ ) as a function of the mean compaction pressure (average of upper and lower punch).

The diagram on the left clearly shows the difference between the tests with and without admixed lubricant. In principle, without lubricant, significantly higher friction coefficients prevail, resulting in higher frictional shear stresses during both, compaction and ejection [14]. This favours the formation of cold welds, which creates grooves when the green compacts are ejected, leading to further increases in the current friction coefficients. As a result, the stripping shear stresses - especially without coating - increase sharply with each pressing cycle until they reach the same level as the compaction pressure. Since the coating types used here reduce the formation of cold welds [21, 22], these processes are less pronounced and lead to lower stripping shear stresses compared to the variant without coating.

The diagram on the right shows an enlarged view of the ejection behaviour as a function of the compaction pressure when admixed lubricant is used. Basically the same trends can be seen as in (Figure 2): within the lower and medium pressure levels, the $\mathrm{MoS}_{2}$-based coating exhibits the lowest stripping shear stresses followed by the DLC-based coating and the variant without coating. In the upper pressure range, the latter show approximately equal results, while the $\mathrm{MoS}_{2}$ coating again leads to the lowest stresses.

In addition, it is noticeable that despite a constant filling height, different compaction pressures occur, with the associated stripping shear stresses behaving mostly proportionally. This change in compaction pressure can 
be attributed to varying powder masses [23], as the powder was filled using a stripping method (filling shoe) without being weighed. A later comparison of the compact masses confirmed this assumption. From this observation, it could be concluded that the standard deviations shown in (Figure 2 right) result from this powder mass variance. However, if the coefficients of determination $\left(R^{2}\right)$ of the power function fits are taken into account, it can be observed that a larger part of the data of the variant without coating cannot be explained by the fit compared to the variants with coating. Consequently, this deviation cannot be attributed to the mass variance, which leads to the conclusion that the two coatings show a higher process stability regarding constant stripping shear stresses.
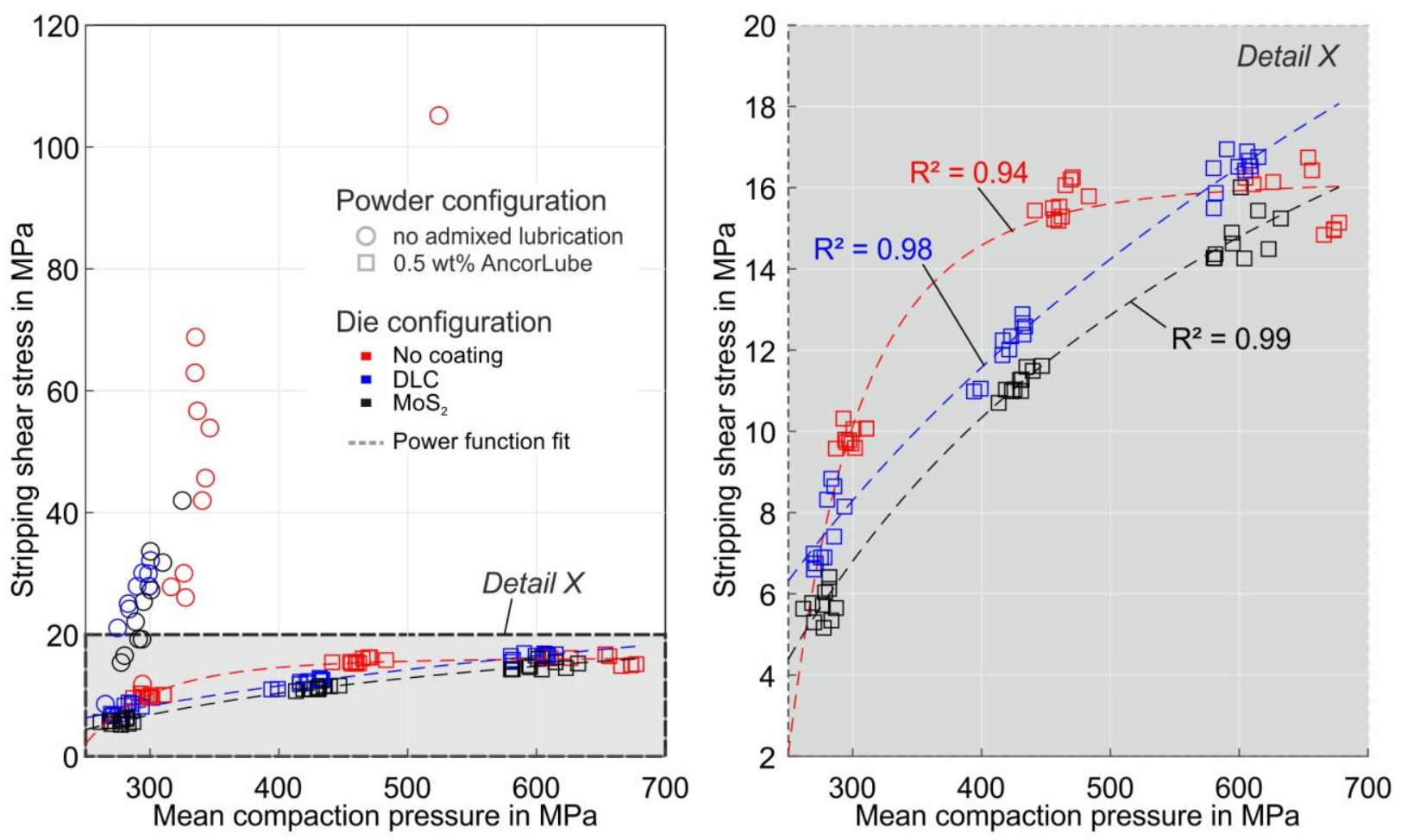

Figure 3 Stripping shear stresses as a function of mean compaction pressures

\section{CONCLUSION}

Experimental investigations on the ejection behaviour of friction-reducing coatings in the die compaction of iron powder with and without admixed lubricant were presented. It is shown that the application of the coatings reduces the ejection loads significantly, when no admixed lubricant is used, and moderately when powder lubrication is applied. In the latter case, when compaction pressure is below $500 \mathrm{MPa}, \mathrm{MoS}_{2}$-based coating exhibits the lowest stripping shear stresses followed by the DLC-based coating and finally the variant without coating. Above $550 \mathrm{MPa}$, the DLC coating and the non-coated variant perform approx. equally well, while the lowest values are again achieved by the $\mathrm{MoS}_{2}$-based coating. However, without lubricant admixture, wear occurs after a few pressing cycles despite the use of coatings, so lubricant cannot be completely avoided. Furthermore, the results indicated a higher process stability when using a coating (for both coatings). For future investigations, a reduction of the admixed lubricant as well as the evaluation of the service life of the coatings are of interest.

\section{ACKNOWLEDGEMENTS}

This contribution is part of a basic research project funded by the German Research Foundation (DFG), project number 403432892. The authors would like to express their gratitude for the financial 


\section{support of this project. Furthermore, the authors would like to thank GKN Sinter Metals Engineering for providing the metal powders.}

\section{REFERENCES}

[1] SCHATT, W., WIETERS, K.-P., KIEBACK, B. Pulvermetallurgie: Technologien und Werkstoffe. 2nd ed. Berlin: Springer; 2007.

[2] ENGSTRÖM, U., SCHNEIDER, E. Metal Powder Solutions to Promote Future Growth of the PM industry. In: World PM2018 proceedings. Beijing, China; 2018.

[3] BEHRENS, B.-A., GASTAN, E., VAHED, N. Application of tool vibration in die pressing of Ti-powder. Production Engineering. 2010, vol. 4, no. 6, pp. 545-551.

[4] GAŠTAN, E. Einfluss von Werkzeugschwingungen auf das Verdichtungsverhalten metallischer Pulver beim Matrizenpressen. Garbsen: PZH, Produktionstechn. Zentrum; 2012.

[5] BOUGUECHA, A., BEHRENS, B.-A. Numerische und experimentelle Untersuchungen zum Matrizenpressen und Sintern von Aluminiumpulver. Materialwissenschaft und Werkstofftechnik. 2012, vol. 43, no. 6, pp. 511-519.

[6] HONG, S.-T., HOVANSKI, Y., LAVENDER, C.A., WEI,L K.S. Investigation of Die Stress Profiles During Powder Compaction Using Instrumented Die. Journal of Mat Engineering and Performance. 2008, vol. 17, no. 3, pp. 382386.

[7] SOLIMANJAD, N., LARSSON, R. Die wall friction and influence of some process parameters on friction in iron powder compaction. Materials Science and Technology. 2013, vol. 19, no. 12, pp. 1777-1782.

[8] LUK, S.H., DAVALA, A.B., KOPECH, H.M. Enhanced green strength material system for ferrous and stainless P/M processing. Advances in Powder Metallurgy and Particulate Materials--1996. 1996, vol. 5, pp. 17.

[9] KORACHKIN, D., GETHIN, D.T., LEWIS, R.W., TWEED, J.H. Friction measurement and lubrication in unloading and ejection stages in powder pressing cycle. Powder Metallurgy. 2013, vol. 51, no. 1, pp. 14-30.

[10] LEMIEUX, P., GÉLINAS, C., POWDER,S R.T.M. Ejection Performance of an Improved Die Wall Lubrication Technology Using Composite Lubricants. In: APMI International Conference on Powder Metallurgy \& Particulate Materials. 2015.

[11] LARSSON, M., RAMSTEDT, M. Lubricants for Compaction of P/M Components. In: PTECH 2003 - 4nd International Latin-American Conference on Powder Technology in São Paulo, Brazil, 2003.

[12] PARIS, V., ST-LAURENT, S., THOMAS, Y. Key Advantages of High Performance Lubricants for the Manufacturing of Powder Metallurgy Parts. In: Proceedings of the 2014 International Conference on Powder Metallurgy \& Particulate Materials. May 18 - 22, Orlando, FL. Princeton, NJ: Metal Powder Industries Federation; 2014.

[13] LARSSON, M., KNUTSSON, P. Efficient Lubricants for Production of High Density PM Components. In: APMA2017 The 4th International Conference on Powder Metallurgy in Asia. Apr. 09-11, 2017, Hsinchu, Taiwan, 2017.

[14] ERNST, E. Axiale Pressvorgänge in der Pulvermetallurgie. VDI Verlag; 1992.

[15] BONNEFOY, V., DOREMUS, P., PUENTE, G. Investigations on friction behaviour of treated and coated tools with poorly lubricated powder mixes. Powder Metallurgy. 2003, vol. 46, no. 3, pp. 224-228.

[16] OLSSON, M. A new test method for measuring the galling resistance between metal powders and die tool materials in powder compaction. Wear. 2011, vol. 273, no. 1, pp. 49-54.

[17] LARSSON, M., AHLIN, A.., OLSSON, K. High performance mixes with new lubricant system. Powder Metallurgy. 2010, vol. 53, no. 2, pp. 103-106.

[18] voestalpine eifeler Coating GmbH, CARBON-X® - Data Sheet. [online]. 2021. [viewed: 2021-02-12]. Available from: https://www.eifeler.com/app/uploads/sites/82/2018/05/CARBON-X DE.pdf.

[19] voestalpine eifeler Coating $\mathrm{GmbH}, \mathrm{MOX} 2 \circledR$ - Data Sheet. [online]. 2021. [viewed: 2021-02-12]. Available from: https://www.eifeler.com/app/uploads/sites/82/2018/05/MOX2 DE.pdf

[20] Ancorsteel ${ }^{\mathrm{TM}} 1000 / 1000 \mathrm{~B} / 1000 \mathrm{C}$ - Data Sheet. [online]. 2021. [viewed: 2021-01-19]. Available from: https://www.gknpm.com/globalassets/downloads/hoeganaes/technical-library/datasheets/datasheets-for-pmmaterials/high-purity-iron-powders/ancorsteel1000.pdf/ 
[21] ZAHID, R., MASJUKI, H.H., VARMAN, M., MUFTI, R.A., KALAM, M.A., GULZAR, M. Effect of Lubricant Formulations on the Tribological Performance of Self-Mated Doped DLC Contacts: A review. Tribology Letters. 2015, vol. 58, no. 2.

[22] BEHRENS, B.-A., MAIER, H.J., HÜBNER, S., BONK, C., ALMOHALLAMI, A., MICKE-CAMUZ, M. Wear Behavior of MoS2 Lubricant Layers During Sheet Metal Forming. Procedia Engineering. 2017, vol. 183, pp. 357-362.

[23] SOKOLOWSKI, P., MILBRATH, A., VITTI, D., FONTANA, S. Industrial performance of a new lubricant for manufacturing PM gears. Metal Powder Report. 2016, vol. 71, no. 3, pp. 180-183. 